Short communication

\title{
Antibodies to Toxoplasma gondii and Leishmania spp. in domestic cats from Luanda, Angola
}

\author{
Ana Patrícia Lopes ${ }^{\mathrm{a}, \mathrm{b}}$, Ana Cristina Oliveira ${ }^{\mathrm{c}}$, Sara Granada ${ }^{\mathrm{c}}$, Filipa T. Rodrigues ${ }^{\mathrm{d}}$, \\ Elias Papadopoulos ${ }^{\mathrm{e}}$, Henk Schallig ${ }^{\mathrm{f}}$, Jitender P. Dubey ${ }^{\mathrm{g}}$, Luís Cardoso ${ }^{\mathrm{a}, *}$

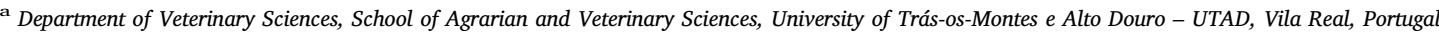 \\ b Animal and Veterinary Research Centre - CECAV, UTAD, Vila Real, Portugal \\ c Clínica Casa dos Animais, Luanda, Angola \\ d School of Agriculture, Polytechnic Institute of Braganza, Bragança, Portugal \\ e School of Veterinary Medicine, Faculty of Health Sciences, Aristotle University of Thessaloniki, Thessaloniki, Greece \\ ${ }^{\mathrm{f}}$ Laboratory for Clinical Parasitology, Department of Medical Microbiology, Academic Medical Centre - AMC, Amsterdam, The Netherlands \\ ${ }^{g}$ Animal Parasitic Diseases Laboratory, Beltsville Agricultural Research Center, Agricultural Research Service, United States Department of Agriculture, Beltsville, MD \\ 20705, USA
}

\section{A R T I C L E I N F O}

\section{Keywords:}

Angola

Antibodies

Cat feline

Leishmania

Luanda

Seroprevalence

Toxoplasma

\begin{abstract}
A B S T R A C T
Toxoplasma gondii and Leishmania spp. are zoonotic protozoa of importance to animal and public health. The present study aimed to assess for the first time the seroprevalence of these zoonotic parasites in a domestic feline population living in Luanda, Angola. One hundred and two cats were sampled at a veterinary medical centre, from May 2014 to February 2016. The age of the cats ranged from 2.5 to 143 months (median: 12 months; interquartile range: 7.5-24). Serum samples were tested for immunoglobulin (Ig) G antibodies to T. gondii at twofold dilutions of $1: 20$ to $1: 2560$ with a modified agglutination test (MAT) commercial kit. The direct agglutination test (DAT) for titration of IgG antibodies specific to Leishmania spp. used a standard freeze-dried antigen at a concentration of $5 \times 10^{7}$ promastigotes per milliliter, following a predefined protocol. Two-fold dilution series ranging from 1:25 to 1:800 were tested, with a cut-off titre of 100 chosen for seropositivity. Four out of 102 cats (3.9\%; 95\% confidence interval [CI]: 1.1-9.7) had antibodies to T. gondii: one had a titer of 20, one a titer of 160 , and two had a titer $\geq 2560$. No cat $(0.0 \%$; CI: $0.0-3.5)$ was found seropositive for Leishmania spp. A statistically significant difference was found between $T$. gondii seroprevalence and Leishmania spp. seroprevalence $(p=0.043)$. The odds of a cat being seropositive to $T$. gondii increased by an average factor of 1.58 for each 1 -year increase in age $(p=0.003)$. The sampled cats were well-cared animals and may not represent the overall feline population of Angola at the national and city levels. The fact that only 12 out of the 102 sampled cats ate or had access to raw or undercooked meat and/or viscera may have reduced the likelihood of finding seropositive results. Under these circumstances, additional studies, including a larger number of cats, are necessary for a more comprehensive assessment of the zoonotic risk posed by these animals in Angola.
\end{abstract}

\section{Introduction}

Domestic cats live in close proximity to humans and can serve as potential reservoirs for agents of zoonotic diseases. Among them, some protozoal infections can cause pathogenic effects in cats and are also of importance to public health. Such zoonotic parasites include Toxoplasma gondii (Dubey, 2010) and Leishmania spp. (Pennisi et al., 2015), causing toxoplasmosis and leishmaniosis, respectively.

Toxoplasma gondii can infect almost all homeothermic animals, but felids are the only definitive hosts of the parasite, playing an important role in the spread of $T$. gondii by excreting millions of oocysts in their faeces into the environment, if they acquire the infection (Dubey, 1997; Dubey, 2010). Although quite prevalent in domestic and wild cats, infections are generally subclinical. However, feline toxoplasmosis may occur with interstitial pneumonia being the most common clinical manifestation and one of the main causes of mortality. Ocular toxoplasmosis in the cat is estimated to occur in about $75 \%$ of infected animals and is frequently associated with systemic infection. Other clinical manifestations include gastrointestinal and neurological changes, hepatitis, pancreatitis and muscular hyperesthesia due to myositis (Dubey and Carpenter, 1993; Hawkins et al., 1997; Davidson, 2000). Infection in immunocompetent people is mainly

\footnotetext{
* Corresponding author at: Departamento de Ciências Veterinárias, UTAD, Quinta de Prados, 5000-801 Vila Real, Portugal.

E-mail address: lcardoso@utad.pt (L. Cardoso).
} 
subclinical, but in immunocompromised individuals and congenitally infected children, toxoplasmosis may be the cause of high morbidity and mortality (Belanger et al., 1999; Avelino et al., 2003). Since seropositive cats are likely to have already excreted $T$. gondii oocysts, serologic surveys for the detection of anti-T. gondii antibodies can be helpful to determine the potential risk of infection in distinct geographical areas (Lucas et al., 1999; Miró et al., 2004).

Leishmania infantum is the agent of zoonotic visceral leishmaniosis, with domestic dogs as its primary reservoir and phlebotomine sand flies as vectors (Quinnell and Courtenay, 2009). Detection of antibodies specific to Leishmania spp. is an important diagnostic tool, with the direct agglutination test (DAT) being suitable for the evaluation of large numbers of serum samples in animals (Schallig et al., 2002; Vilhena et al., 2014). The first case of feline leishmanial infection was described in a domestic cat from Algiers, Algeria (Sergent et al., 1912). Still in Africa, epidemiological surveys in pet and stray cats and clinical cases of feline leishmaniosis have been more recently reported from Egypt (Michael et al., 1982; Morsy et al., 1988; Morsy and Abou el Seoud, 1994).

Despite the fact that both parasites have been found to infect humans and dogs in Angola (Sabido et al., 1963; Martins et al., 1976; Jimenez et al., 1994; Caeiro et al., 1998; Vilhena et al., 2014; Lobo et al., 2016), no reports are known on T. gondii and/or Leishmania spp. infections in cats from the country. Under this circumstance, the present study aimed at assessing the seroprevalence of these two zoonotic parasites in a sample of the domestic feline population living in the Angolan capital and main city, Luanda.

\section{Materials and methods}

One hundred and two cats were sampled at a veterinary medical centre in Luanda, Angola, from May 2014 to February 2016. Available categorical data are presented in Table 1. The age of cats ranged from 2.5 to 143 months (median: 12 months; interquartile range: 7.5-24). This study was ethically approved by the scientific council of the Vasco da Gama University School as complying with the Portuguese legislation for the protection of animals (Law no. 92/1995 and Decree-Law $n^{\circ}$ $113 / 2013)$. Owners provided their signed informed consent for inclusion of their animals in the study.

Serum samples were tested for immunoglobulin (Ig) G antibodies to T. gondii at two-fold dilutions of $1: 20$ to $1: 2560$ with a modified agglutination test (MAT) commercial kit (Toxo-Screen DA bioMérieux, Lyon, France) according to the manufacturer's instructions. Positive and negative control samples, supplied with the kit, were included in each plate. Results obtained with the MAT were expressed as an antibody titre, i.e. the reciprocal of the highest dilution at which agglutination (at least one half of the well's diameter) was still visible after 5-18 h incubation at room temperature. A cut-off titre of 20 (2 IU/ $\mathrm{ml}$ in relation to a World Health Organization international reference serum) was chosen to maximize both sensitivity and specificity of the test (Dubey et al., 1995; Lopes et al., 2008).

The DAT for titration of IgG antibodies specific to Leishmania spp. used a standard freeze-dried antigen at a concentration of $5 \times 10^{7}$ promastigotes per milliliter (Academic Medical Centre, Amsterdam, The Netherlands), following a predefined protocol (Schallig et al., 2002). Serum two-fold dilution series ranging from 1:25 to 1:800 were tested. A cut-off titre of 100 was chosen for seropositivity (Cardoso et al., 2010).

The Fisher's exact test was used to compare seropositivity values among categories of the same independent variables and a probability $(p)$ value $<0.05$ was considered as statistically significant. Exact binomial 95\% confidence intervals (CI) were established for partial and total seroprevalence values. Univariable logistic regression analysis was used to identify risk factors for seropositivity, calculating odds ratios (OR) and their 95\% CI (Petrie and Watson, 2013). Analyses were done using the StatLib and IBM SPSS Statistics 20 software.
Table 1

Toxoplasma gondii seroprevalence in cats from Luanda, Angola.

\begin{tabular}{|c|c|c|c|}
\hline Variable/category & $\begin{array}{l}\text { No. of cats } \\
(\%) \text { tested }\end{array}$ & $\begin{array}{l}\text { Percentage }(n) \text { of } \\
\text { positive cats }\end{array}$ & $95 \% \mathrm{CI}$ \\
\hline Gender & 100 & & \\
\hline Female & $56(56.0)$ & $5.4(3)$ & $1.1-14.9$ \\
\hline Male & $44(44.0)$ & $2.3(1)$ & $0.1-12.0$ \\
\hline Breed & 95 & & \\
\hline Mixed & $91(95.8)$ & $1.1(1)$ & $0.0-6.0$ \\
\hline Defined $^{\mathrm{a}}$ & $4(4.2)$ & $25.0(1)$ & $0.6-80.6$ \\
\hline Age group & 99 & & \\
\hline Juvenile ${ }^{b}$ & 49 (49.5) & $0.0(0)$ & $0.0-7.2$ \\
\hline Adult ${ }^{c}$ & $50(50.5)$ & $8.0(4)$ & $2.2-19.2$ \\
\hline Hair length & 101 & & \\
\hline Short & $84(83.2)$ & $3.6(3)$ & $0.7-10.1$ \\
\hline Medium or long & $17(16.8)$ & $5.9(1)$ & $0.2-28.7$ \\
\hline Housing & 101 & & \\
\hline Indoors & $37(36.6)$ & $2.7(1)$ & $0.1-14.2$ \\
\hline Outdoors or mixed & $64(63.4)$ & $4.7(3)$ & $1.0-13.1$ \\
\hline $\begin{array}{l}\text { Access to raw or undercooked } \\
\text { meat and/or viscera }\end{array}$ & 101 & & \\
\hline No & $90(89.1)$ & $4.4(4)$ & $1.2-11.0$ \\
\hline Yes & $11(10.9)$ & $0.0(0)$ & $0.0-28.5$ \\
\hline Contact with other animals ${ }^{\mathrm{d}}$ & 96 & & \\
\hline No & $20(20.8)$ & $5.0(1)$ & $0.1-24.9$ \\
\hline Yes & $76(79.2)$ & $3.9(3)$ & $0.8-11.1$ \\
\hline Clinical status & 101 & & \\
\hline Apparently healthy & $88(87.1)$ & $2.3(2)$ & $0.3-8.0$ \\
\hline Sick $^{\mathrm{e}}$ & $13(12.9)$ & $15.4(2)$ & $1.9-45.4$ \\
\hline Total & $102(100)$ & $4(3.9)$ & $1.1-9.7$ \\
\hline
\end{tabular}

CI: confidence interval; ND: not determined.

${ }^{\text {a }}$ Comprising 2 Persian and 2 Siamese cats.

b [2.5-11.5 months].

c [12-143 months].

d Including cats, dogs, rodents and/or birds.

e Clinical manifestations and laboratory abnormalities compatible with toxoplasmosis and/or leishmaniosis included: anemia, anorexia/hyporexia, cough, cutaneous lesions, diarrhea, fever, leukocytosis, leukopenia, neurological disorders, ocular signs, thrombocytopenia, weight loss and vomiting.

\section{Results}

In accordance with the established cut-off value (MAT 20), four out of 102 cats (3.9\%; CI: 1.1-9.7) had antibodies to T. gondii: one had a titer of 20 , one a titer of 160 , and two had a titer $\geq 2560$. On the other hand, no cat (0.0\%; CI: 0.0-3.5) was found seropositive for Leishmania spp. A statistically significant difference $(p=0.043)$ was found between seropositivity to $T$. gondii and to Leishmania spp.

Statistical analyses revealed no significant differences of seropositivity to T. gondii for categories within gender, breed, age group, hair length, housing, ingestion of raw or undercooked meat and/or viscera, contact with other animals and presence of clinical signs compatible with toxoplasmosis and/or leishmaniosis (Table 1). By univariable logistic regression, the odds of a cat being seropositive to $T$. gondii increased by an average factor of 1.58 (95\% CI: $1.17-2.15 ; p=0.003$ ) for each 1-year increase in age.

\section{Discussion}

Information from Angola on T. gondii and Leishmania spp. infections in animals and humans is scarce. The present sero-survey represents the first epidemiological study of T. gondii and Leishmania spp., two important zoonotic protozoan parasites, carried out in cats from Luanda and also from Angola. Other international studies corroborate the results obtained for $T$. gondii infection. Also by using the MAT, low seroprevalence figures of $9.3 \%(14 / 150)$ and $10.1 \%$ (35/348) were also reported in domestic cats from Durango, Mexico (Dubey et al., 2009) 
and from Bangkok, Thailand (Sukhumavasi et al., 2012), respectively. This low seroprevalence was attributed to low T. gondii positivity in the local small animal populations. We cannot exclude that this can also be the case of the present study. However, further studies are necessary in other host species from Luanda.

Using an enzyme-linked immunosorbent assay (ELISA), Lobetti and Lappin (2012) described a seroprevalence of $17.6 \%$ in 102 cats from South Africa. We had previously found a $35.8 \%$ seroprevalence in domestic cats from Portugal using the same serological test (Lopes et al., 2008). More recently, also by using the MAT, considerably higher figures of $85.4 \%$ (Tiao et al., 2013) and 91.7\% (Dubey et al., 2013) were reported in cats from Ethiopia, and of 95.5\% in Cairo, Egypt (AlKappany et al., 2011). Differences in the feline T. gondii seroprevalence levels among countries may be due to ecological and geographical factors, as well as to feeding and lifestyle of the studied animals, since most cats from Ethiopia and Egypt roamed freely (Dubey et al., 2013). According to Dubey (2010), factors affecting the prevalence of T. gondii in cats are not fully understood and need further investigation.

By using MAT and a cut-off titre of 20, antibodies to T. gondii were found in $15.5 \%$ out of 103 dogs from Luanda (Lopes et al., 2014), representing a statistically significant difference to the present results in cats $(3.9 \% ; p=0.005)$. On the other hand, seropositivity of Leishmania spp. in cats $(0.0 \%)$ is in line with that detected in the same 103 dogs (1.9\%; Vilhena et al., 2014), since no significant difference could be found $(p=0.157)$.

Only three reports on human $T$. gondii infection are available from Angola (Martins and Abranches, 1976; López et al., 1992; Lobo et al., 2016), with no data available from animal species other than dogs and now cats (this study). Seroprevalence varied from $71.5 \%$ in young people aged 13-16 years old (López et al., 1992) to $27.3 \%$ in pregnant women from Luanda (Lobo et al., 2016), complementarily suggesting that $72.7 \%$ of women in childbearing age are susceptible to primoinfection by the parasite. The climate of different geographical locations affects the transmission dynamics of $T$. gondii in the environment, as oocysts cannot become sporulated, survive and remain infectious without favorable conditions (Dubey, 2010).

No statistically significant different seroprevalence values could be demonstrated for $T$. gondii among the categories within gender, breed, age group, hair length, housing, access to raw and undercooked meat and/or viscera, contact with other animals, and the presence of clinical signs suggesting clinical toxoplasmosis or leishmaniosis (Table 1). Although there were only a small number of seropositive animals, these observations suggest that those categories would not represent risk factors for $T$. gondii and that all cats are equally exposed to infection. Similar findings were obtained by Bresciani et al. (2007), Coelho et al. (2011) and Cardia et al. (2013), in cats from Brazil. Nevertheless, seroprevalence of infection in domestic cats has been found to vary with their lifestyle (wild, stray or domestic), age, serological test used and geographical location (Gauss et al., 2003). Cats of all ages, gender and breeds are susceptible to infection (Dubey et al., 1977; Dorny et al., 2002). In the present study, the odds of a cat being seropositive increased by an average factor of 1.58 for each 1year increase in age. It can be assumed that increasingly older cats have had more chances to eat tissues of infected animals or to have contact to the surrounding environment potentially contaminated with $T$. gondii oocysts (Lopes et al., 2014).

A small number of human visceral leishmaniosis cases, some of them presumably autochthonous (Sabido et al., 1963; Caeiro et al., 1998) and one typed as being caused by L. infantum (Jimenez et al., 1994), have also been reported from Angola. During the 1960s and 1970s, three cases of canine leishmaniosis occurred in imported dogs and two other cases were presumed as autochthonous from the country (Caeiro et al., 1998). More recently, two dogs presenting clinical signs compatible with leishmaniosis were found seropositive to Leishmania spp. in Luanda. One of the dogs had been imported from Portugal, but the other one had never left Angola. This latter animal was also found polymerase chain reaction- positive and confirmed to be infected with L. infantum by sequence analysis (Vilhena et al., 2014).

In the present study, sampled cats were well-cared animals and may not represent the overall feline population of Angola at the national and city levels. Studies in Europe have shown that cats receiving raw meat have a significantly higher risk of being seropositive to T. gondii (Svoboda and Svobodová, 1987; Lopes et al., 2008). According to Lucas et al. (1999), diets containing meat or raw viscera are predisposing factors of the infection. In the present study, the circumstance that only $12(11.8 \%)$ out of the 102 cats had access to raw or undercooked meat and/or viscera may have reduced the likelihood of finding more seropositive results. Under this circumstance, the seroprevalence of $T$. gondii and even that of Leishmania spp. might be expected to be higher in other populations of cats from Angola.

In conclusion, this is the first epidemiological study of $T$. gondii and Leishmania spp. in cats from Luanda and Angola. Low seroprevalence values were found, but the sampled cats may not represent the overall feline population at the national and city levels. Additional studies, including a larger number of cats, different species of domestic animals and wildlife, and also complementary molecular detection methods are necessary for a more comprehensive assessment of the zoonotic risk posed by these animals as potential reservoirs of $T$. gondii and Leishmania spp. in Angola.

\section{Conflict of interest statement}

The authors declare no conflict of interest.

\section{Acknowledgements}

The authors would like to express their gratitude to Hugo Vilhena for his logistic support. This work was sponsored by the Foundation for Science and Technology (FCT), Ministry of Education and Science, Portugal, under the Projects UID/CVT/00772/2013 and UID/CVT/ 0772/2016.

\section{References}

Al-Kappany, Y.M., Lappin, M.R., Kwok, O.C., Abu-Elwafa, S.A., Hilali, M., Dubey, J.P., 2011. Seroprevalence of Toxoplasma gondii and concurrent Bartonella spp. feline immunodeficiency virus, feline leukemia virus, and Dirofilaria immitis infections in Egyptian cats. J. Parasitol. 97, 256-258.

Avelino, M.M., Campos, D., Parada, J.C.B., Castro, A.M., 2003. Pregnancy as a risk factor for acute toxoplasmosis seroconversion. Eur. J. Obstet. Gynecol. Reprod. Biol. 108, 19-24.

Belanger, F., Derouin, F., Grangeot-Keros, L., Meyer, L., 1999. Incidence and risk factors of toxoplasmosis in a cohort of human immunodeficiency virus-infected patients: 1988-1995. HEMOCO and SEROCO Study Groups. Clin. Infect. Dis. 28, 575-581.

Bresciani, K.D., Gennari, S.M., Serrano, A.C., Rodrigues, A.A., Ueno, T., Franco, L.G., Perri, S.H., Amarante, A.F., 2007. Antibodies to Neospora caninum and Toxoplasma gondii in domestic cats from Brazil. Parasitol. Res. 100, 281-285.

Caeiro, V.M.P., Velho, C.F., de Oliveira, A.F., Bastos, J.G.C., 1998. Um caso mais de Kalaazar em Angola. Med. Vet. 2, 31-39.

Cardia, D.F., Camossi, L.G., Neto Lda, S., Langoni, H., Bresciani, K.D., 2013. Prevalence of Toxoplasma gondii and Leishmania spp. infection in cats from Brazil. Vet. Parasitol. 197, 634-637.

Cardoso, L., Lopes, A.P., Sherry, K., Schallig, H., Solano-Gallego, L., 2010. Low seroprevalence of Leishmania infantum infection in cats from northern Portugal based on DAT and ELISA. Vet. Parasitol. 174, 37-42.

Coelho, W.M., do Amarante, A.F., Apolinário Jde, C., Coelho, N.M., de Lima, V.M., Perri, S.H., Bresciani, K.D., 2011. Seroepidemiology of Toxoplasma gondii, Neospora caninum, and Leishmania spp. infections and risk factors for cats from Brazil. Parasitol. Res. 109, 1009-1013.

Davidson, M.G., 2000. Toxoplasmosis. Vet. Clin. North Am. Small Anim. Pract. 30, 1051-1062.

Dorny, P., Speybroeck, N., Verstraete, S., Baeke, M., De Becker, A., Berkvens, D., Vercruysse, J., 2002. Serological survey of Toxoplasma gondii, feline immunodeficiency virus and feline leukaemia virus in urban stray cats in Belgium. Vet. Rec. 151, 626-629.

Dubey, J.P., Carpenter, J.L., 1993. Histologically confirmed clinical toxoplasmosis in cats: 100 cases (1952-1990). J. Am. Vet. Med. Assoc. 203, 1556-1566.

Dubey, J.P., Hoover, E.A., Walls, K.W., 1977. Effect of age and sex on the acquisition of immunity to toxoplasmosis in cats. J. Protozool. 24, 184-186.

Dubey, J.P., Lappin, M.R., Thulliez, P., 1995. Long term antibody responses of cats fed 
Toxoplasma gondii tissue cysts. J. Parasitol. 81, 887-893.

Dubey, J.P., Velmurugan, G.V., Alvarado-Esquivel, C., Alvarado-Esquivel, D., RodríguezPeña, S., Martínez-García, S., González-Herrera, A., Ferreira, L.R., Kwok, O.C., Su, C., 2009. Isolation of Toxoplasma gondii from animals in Durango, Mexico. Parasitology 95, 319-322.

Dubey, J.P., Darrington, C., Tiao, N., Ferreira, L.R., Choudhary, S., Molla, B., Saville, W.J., Tilahun, G., Kwok, O.C., Gebreyes, W.A., 2013. Isolation of viable Toxoplasma gondii from tissues and feces of cats from Addis Ababa, Ethiopia. J. Parasitol. 99, 56-58.

Dubey, J.P., 1997. Tissue cyst tropism in Toxoplasma gondii: a comparison of tissue cyst formation in organs of cats, and rodents fed oocysts. Parasitology 115, 15-20.

Dubey, J.P., 2010. Toxoplasmosis of Animals and Humans, 2nd ed. CRC Press, Boca Raton $336 \mathrm{pp}$.

Gauss, C.B.L., Almería, S., Ortuño, A., Garcia, F., Dubey, J.P., 2003. Seroprevalence of Toxoplasma gondii antibodies in domestic cats from Barcelona, Spain. J. Parasitol. 89, 1067-1068.

Hawkins, E.C., Davidson, M.G., Meuten, D.J., Rottman, J.B., Kennedy-Stoskopf, S., Levy, J.K., Ritchey, J.W., Cullins, L.D., Tompkins, M.B., 1997. Cytologic identification of Toxoplasma gondii in bronchoalveolar lavage fluid of experimentally infected cats. J. Am. Vet. Med. Assoc. 210, 648-650.

Jimenez, M., Puente, S., Gutierrez-Solar, B., Martinez, P., Alvar, J., 1994. Visceral leishmaniasis in Angola due to Leishmania (Leishmania) infantum. Am. J. Trop. Med. Hyg. 50, 687-692.

López, R., Contreras, R., Font, L., Vega, O., 1992. Presence of antibodies against Toxoplasma gondii in adolescents from the African continent. Rev. Latinoam. Microbiol. 34, 49-52.

Lobetti, R., Lappin, M.R., 2012. Prevalence of Toxoplasma gondii, Bartonella species and haemoplasma infection in cats in South Africa. J. Feline Med. Surg. 14, 857-862.

Lobo, M.L., Patrocinio, G., Sevivas, T., De Sousa, B., Matos, O., 2016. Portugal and Angola: similarities and differences in Toxoplasma gondii seroprevalence and risk factors in pregnant women. Epidemiol. Infect. 9, 1-11.

Lopes, A.P., Cardoso, L., Rodrigues, M., 2008. Serological survey of Toxoplasma gondii infection in domestic cats from northeastern Portugal. Vet. Parasitol. 155, 184-189.

Lopes, A.P., Granada, S., Oliveira, A.C., Brancal, H., Dubey, J.P., Cardoso, L., Vilhena, H., 2014. Toxoplasmosis in dogs: first report of Toxoplasma gondii infection in any animal species in Angola. Pathog. Glob. Health 108, 344-346.

Lucas, S.R., Hagiwara, M.K., Loureiro, V., Ikesaki, J.Y., Birgel, E.H., 1999. Toxoplasma gondii infection in Brazilian domestic outpatient cats. Rev. Inst. Med. Trop. Sao Paulo 41, 221-224.

Martins, J., Abranches, P., 1976. Infeccão toxoplásmica em indivíduos de Huambo, Angola. An. Inst. Hig. Med. Trop. (Lisb.) 4, 111-112.

Michael, S.A., Morsy, T.A., El-Seoud, S.F., Saleh, M.S., 1982. Leishmaniasis antibodies in stray cats in Ismailiya Governorate, Egypt. J. Egypt. Soc. Parasitol. 12, 283-286.
Miró, G., Montoya, A., Jiménez, S., Frisuelos, C., Mateo, M., Fuentes, I., 2004. Prevalence of antibodies to Toxoplasma gondii and intestinal parasites in stray: farm and household cats in Spain. Vet. Parasitol. 126, 249-255.

Morsy, T.A., Abou el Seoud, S.M., 1994. Natural infection in two pet cats in a house of a zoonotic cutaneous leishmaniasis patient in Imbaba area, Giza Governorate, Egypt. J. Egypt. Soc. Parasitol. 24, 199-204.

Morsy, T.A., Michael, S.A., Makhlouf, L.M., el Sibai, M.M., 1988. Leishmania infection sought in non human hosts in Suez Governorate, Egypt. J. Egypt. Soc. Parasitol. 18, 539-545.

Pennisi, M.G., Cardoso, L., Baneth, G., Bourdeau, P., Koutinas, A., Miró, G., Oliva, G., Solano-Gallego, L., 2015. LeishVet update and recommendations on feline leishmaniosis. Parasit. Vectors 8, 302.

Petrie, A., Watson, P., 2013. Statistics for Veterinary and Animal Science, 3rd ed. WileyBlackwell, Oxford $412 \mathrm{pp}$

Quinnell, R.J., Courtenay, O., 2009. Transmission, reservoir hosts and control of zoonotic visceral leishmaniasis. Parasitology 136, 1915-1934.

Sabido, F., Fraga de Azevedo, J., Pinto, M.R., 1963. Um caso de Kala-azar possivelmente contraído em Angola. J. Soc. Cienc. Med. Lisb. 127, 796-826.

Schallig, H.D.F.H., Schoone, G.J., Beijer, E.G.M., Kroon, C.C.M., Hommers, M., Özbel, Y., Özensoy, S., da Silva, E.S., Cardoso, L.M., da Silva, E.D., 2002. Development of a fast agglutination screening test (FAST) for the detection of anti-Leishmania antibodies in dogs. Vet. Parasitol. 109, 1-8.

Sergent, E., Sergent, E., Lombard, J., Quilichini, M., 1912. La leishmaniose à Alger. Infection simultanée d'un enfant, d'un chien et d'un chat dans la même habitation. Bull. Soc. Pathol. Exot. 5, 93-98.

Sukhumavasi, W., Bellosa, M.L., Lucio-Forster, A., Liotta, J.L., Lee, A.C., Pornmingmas, P. Chungpivat, S., Mohammed, H.O., Lorentzen, L., Dubey, J.P., Bowman, D.D., 2012. Serological survey of Toxoplasma gondii, Dirofilaria immitis, Feline Immunodeficiency Virus (FIV) and Feline Leukemia Virus (FeLV) infections in pet cats in Bangkok and vicinities, Thailand. Vet. Parasitol. 188, 25-30.

Svoboda, M., Svobodová, V., 1987. Effects of breed, sex, age, management and other nutrition on the incidence of Toxoplasma gondii in dogs and cats. Acta Vet. Brno. 56, 315-330.

Tiao, N., Darrington, C., Molla, B., Saville, W.J., Tilahun, G., Kwok, O.C., Gebreyes, W.A., Lappin, M.R., Jones, J.L., Dubey, J.P., 2013. An investigation into the seroprevalence of Toxoplasma gondii, Bartonella spp., feline immunodeficiency virus (FIV), and feline leukaemia virus (FeLV) in cats in Addis Ababa, Ethiopia. Epidemiol. Infect. 141, 1029-1033.

Vilhena, H., Granada, S., Oliveira, A.C., Schallig, H.D., Nachum-Biala, Y., Cardoso, L., Baneth, G., 2014. Serological and molecular survey of Leishmania infection in dogs from Luanda, Angola. Parasit. Vectors 7, 114. 